\title{
Determining mutations in G6PC and SLC37A4 genes in a sample of Brazilian patients with glycogen storage disease types la and $\mathrm{Ib}$
}

\author{
Marcelo Paschoalete Carlin ${ }^{1}$, Daniel Zanetti Scherrer ${ }^{1}$, Adriana Maria Alves De Tommaso ${ }^{2}$, \\ Carmen Silvia Bertuzzo ${ }^{1}$ and Carlos Eduardo Steiner ${ }^{1}$ \\ ${ }^{1}$ Departamento de Genética Médica, Faculdade de Ciências Médicas, Universidade de Campinas, \\ Campinas, SP, Brazil. \\ ${ }^{2}$ Departamento de Pediatria, Faculdade de Ciências Médicas, Universidade de Campinas, Campinas, \\ SP, Brazil.
}

\begin{abstract}
Glycogen storage disease (GSD) comprises a group of autosomal recessive disorders characterized by deficiency of the enzymes that regulate the synthesis or degradation of glycogen. Types la and Ib are the most prevalent; while the former is caused by deficiency of glucose-6-phosphatase (G6Pase), the latter is associated with impaired glucose-6-phosphate transporter, where the catalytic unit of G6Pase is located. Over 85 mutations have been reported since the cloning of G6PC and SLC37A4 genes. In this study, twelve unrelated patients with clinical symptoms suggestive of GSDla and lb were investigated by using genetic sequencing of G6PC and SLC37A4 genes, being three confirmed as having GSD la, and two with GSD lb. In seven of these patients no mutations were detected in any of the genes. Five changes were detected in G6PC, including three known point mutations (p.G68R, p.R83C and p.Q347X) and two neutral mutations (c.432G > A and c.1176T > C). Four changes were found in SLC37A4: a known point mutation (p.G149E), a novel frameshift insertion (c.1338_1339insT), and two neutral mutations (c.1287G > A and c.1076-28C > T). The frequency of mutations in our population was similar to that observed in the literature, in which the mutation p.R83C is also the most frequent one. Analysis of both genes should be considered in the investigation of this condition. An alternative explanation to the negative results in this molecular study is the possibility of a misdiagnosis. Even with a careful evaluation based on laboratory and clinical findings, overlap with other types of GSD is possible, and further molecular studies should be indicated.
\end{abstract}

Keywords: DNA-based diagnosis, glycogen storage disease, G6PC, SLC37A4, mutation.

Received: February 27, 2013; Accepted:October 11, 2013.

The transformation of glucose into glycogen occurs by chemical reactions carried out by specific enzymes (Diament et al., 1994), and a deficiency in one of these leads to the accumulation of glycogen, resulting in hereditary disorders known as glycogen storage diseases (GSD) or glycogenosis (Rubin et al., 2006). There are currently 12 types of GSD, presenting differences in age of onset of symptoms, affected organs, specific enzyme defect, and clinical severity, and each GSD is named after specific enzyme defect and organ impairment (Hicks et al., 2011).

Deficiency in glucose-6-phosphatase (G6Pase, EC 3.1.3.9) activity causes GSD type I (GSD1), which is responsible for more than $90 \%$ of the cases, affecting mainly the liver and the kidneys. In addition to being a key enzyme in the regulation of blood glucose homeostasis, catalyzing the final steps of glycogenolysis and gluconeogenesis

Send correspondence to Carlos Eduardo Steiner. Departamento de Genética Médica, Faculdade de Ciências Médicas, Universidade de Campinas, Rua Tessália Vieira de Camargo 126, 13083-887 Campinas, SP, Brazil. E-mail: steiner@fcm.unicamp.br.
(Chou et al., 2002), it is also associated with the endoplasmic reticulum (ER) and functions as a multicomponent system (van Schaftingen and Gerin, 2002).

The catalytic subunit of the system is located inside the ER and its defect causes subtype Ia (GSD Ia; OMIM 232200) (Lei et al., 1993). Additionally, there are transporters for the entry of substrate glucose-6-phosphate (G6P) into the ER and for the exit of the products, phosphate and glucose. Defects in these transporters cause subtype Ib (GSD Ib, OMIM 232220) (Gerin et al., 1997). The mechanism of ER membrane glucose transport remains unknown (Froissart et al., 2011).

The disease follows autosomal recessive inheritance and has an incidence of $1 / 100,000$ to $1 / 400,000$ live births, with up to $80 \%$ of the cases represented by subtype Ia (Chen, 2001; Hicks et al., 2011). Patients with GSD Ia and Ib manifest a nearly identical metabolic phenotype, including hypoglycemia, hepatomegaly, hyperuricemia, lactic acidemia and hyperlipidemia (Moses, 1990), but GSD Ib patients also present neutropenia and myeloid dysfunction, 
and these individuals are susceptible to recurrent bacterial infections, aphthous stomatitis, and inflammatory bowel disease (Visser et al., 2000). Nonetheless, neutropenia is not manifested by all GSD Ib patients (Kure et al., 2000; Martens et al., 2006). It is seen in only $20 \%$ of cases (Gitzelmann and Bosshard, 1993), and it has been proposed that it could be due to SLC37A4 mutations with residual transport activity (Kure et al., 2000). Clinical differentiation between GSD types $1 \mathrm{a}, 1 \mathrm{~b}$ and 3 may not always be possible (Tamhankar et al., 2012).

A biochemical essay for GSDI is useful to confirm the diagnosis and to recommend treatment; routine tests, however, do not allow the determination of the disease subtype (Fernandes et al., 1969). Furthermore, since the enzyme is not expressed in tissues such as fibroblasts or lymphocytes, their measurement is only possible by liver biopsy (Burchell, 1990), an invasive procedure considered stressful by many families. cDNA cloning of G6PC and SLC37A4 allowed the screening of mutations responsible for subtypes Ia and Ib, which enabled establishing an alternative, less invasive diagnosis based on molecular biology techniques using blood samples (Parvari et al., 1997). A diagnostic flowchart for this procedure was created based on mutation analysis combined with clinical and biochemical abnormalities (Rake et al., 2000).

In the present study, we aimed to identify mutations in G6PC and SLC37A4 genes in patients clinically suspected of having GSD Ia and Ib, and to compare the molecular findings with clinical diagnosis in these individuals and classify their disease types and subtypes.

Twelve unrelated subjects with clinical features suggestive of GSD Ia or Ib were studied. Inclusion criteria were based on typical clinical and laboratory findings, consisting of recurrent episodes of hypoglycemia associated with hepatomegaly, "doll face", and biochemical changes including hypoglycemia, hypertriglyceridemia, hypercholesterolemia, and hyperuricemia, with or without neutropenia. Patients were of diverse ethnicities, including Iberian, Italian, Afro-Brazilian, and Amerindian background. An Ashkenazi origin was not referred. This study was approved by the Institutional Review Board, and all patients or their legal guardians gave informed consent before inclusion.

Genomic DNA was extracted from peripheral blood leukocytes by using the standard phenol/chloroform method. Exons of the G6PC (five exons and 357 amino acids) and SLC37A4 (eleven exons and 450 aminoacids) genes and their flanking intron/exon junctions were amplified by polymerase chain reaction (PCR) using previously described primers (Lei et al., 1993; Marcolongo et al., 1998).

The PCR fragments were directly sequenced using a MegaBACE1000 ${ }^{\circledR}$ DYEnamic ET(Amersham Biosciences) apparatus. Sequencing was performed on both strands, and the analysis was done twice for each fragment, aiming to incresase confidence of the result. The obtained sequences were compared with the sequences of the G6PC (ENST00000253801) and SLC37A4 (ENST0000330775) always available in the Ensembl genome browser.

The present study confirmed the diagnosis of GSD Ia in three patients, and of GSD Ib in two others.

Four known changes were detected in $G 6 P C$, consisting of one missense, one nonsense and two neutral mutations: c.432G $>\mathrm{A}(\mathrm{rs} 161628)$ and c.1176T $>\mathrm{C}$ (rs2229611). Three individuals presented the p.R83C (c.326C > T) mutation (located in exon 2), two of them being homozygous and the other one compound heterozygous. A neutral mutation in exon five was found in the remaining allele of this last patient (p.Q347X; c. $1118 \mathrm{C}>\mathrm{T})$.

Concerning the SLC37A4 gene, four changes were found, corresponding to a known missense mutation, a novel insertion (frameshift) and two neutral mutations: c. $1287 \mathrm{G}>\mathrm{A}(\mathrm{rs} 8192696)$ and c.1076-28C $>\mathrm{T}$ (rs201063857). The p.G149E (c.654G > A) mutation in exon four was found in one homozygous patient. In another homozygous individual, the insertion of a $\mathrm{T}$ base between nucleotides 1338 and 1339 was detected in exon eleven. This change results in a reading frame modification and creates a premature stop codon (Figure 1).

In addition to these mutations, some SNPs were also identified in this sample. In the remaining seven individuals, no disease causative mutation was found. Clinical and molecular data are summarized in Table 1.

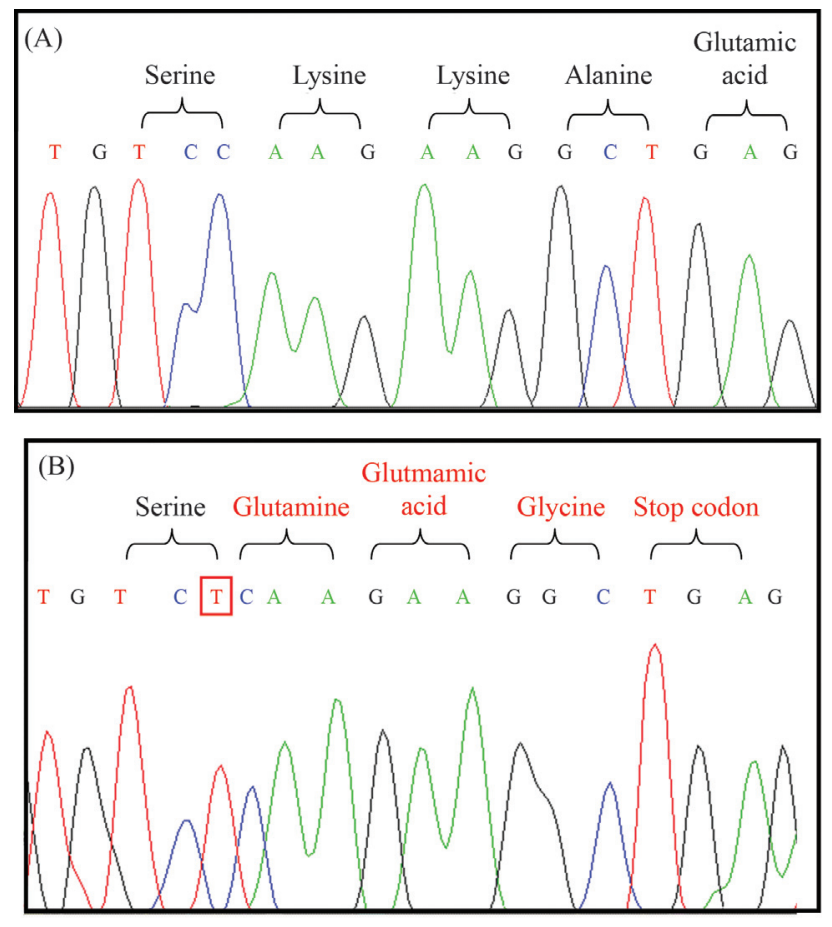

Figure 1 - Electropherogram showing the homozygous insertion in exon 11; from the point of insertion, all following codons convert into other amino acids, resulting in a premature stop codon; (A) normal sequence and (B) homozygous patient. 


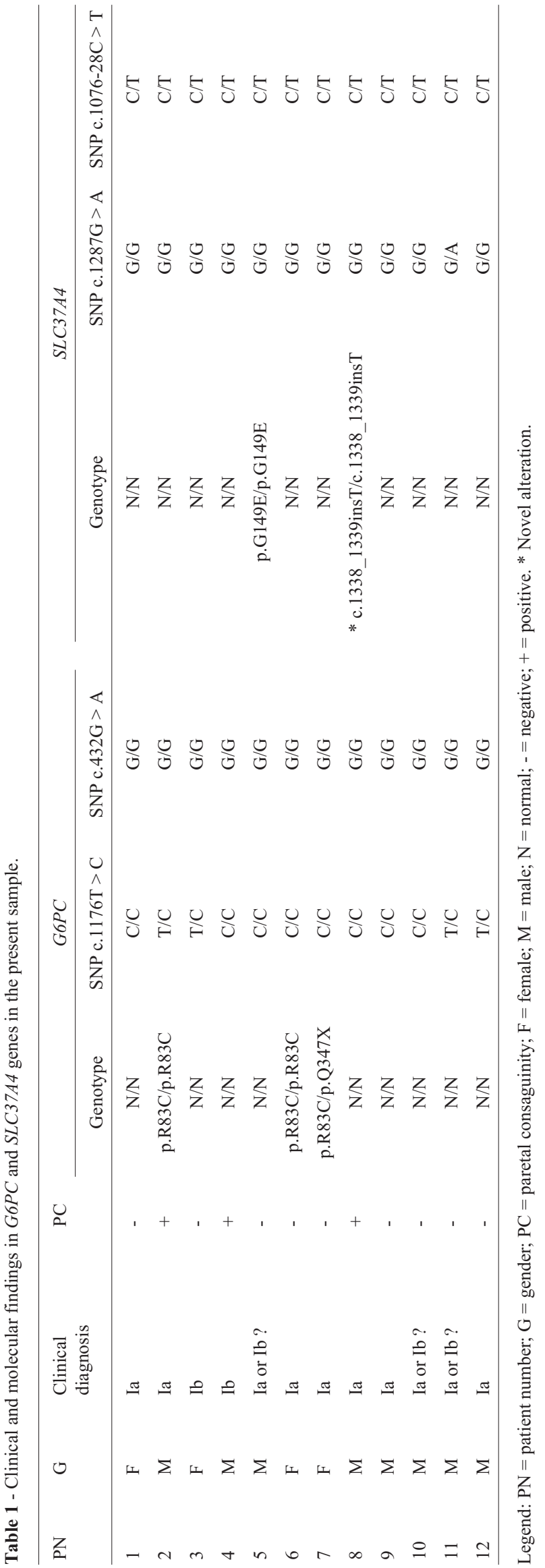

The above results show that GSD1a was more prevalent than GSDIb in our case series. Considering the G6PC gene, p.R83C alters the amino acid that contributes to the active center of the enzyme. It is considered one of the most frequent mutations, seen both worldwide (Lei et al., 1995a,b; Parvari et al., 1995, 1997; Stroppiano et al., 1999; Rake et al., 2000) and in Brazil (Reis et al., 2001). The present results corroborate these findings identify this as the most prevalent one among the mutant alleles. This being the case, the evaluation of this mutation by RFLP may allow the disease diagnosis without the need for automated sequencing, reducing cost and time of examination, since the restriction site mutation alters the enzyme HgaI cleavage pattern.

The remaining change (p.Q347X), already described in the literature, leads to truncation of the carboxy-terminal 11 amino acid residues in human G6Pase and inactivates its activity (Lei et al., 1994). It is also frequently observed in individuals with impaired G6Pase, being common among Caucasian patients in the United States (Lei et al., 1995a) and Europe (north and south), representing $70 \%$ of all mutant alleles in these regions (Chevalier-Porst et al., 1996; Rake et al., 1999). Nevertheless, in the present sample, it was detected only in one allele of one patient, this being compound heterozygous for $\mathrm{p} . \mathrm{R} 83 \mathrm{C}$.

In the SLC37A4 gene, a missense mutation p.G149E and an insertion c.1338_1339insT were found, each one in an individual, both homozygous. In addition to these, SNP c.1076-28C > T (rs201063857) was recently reported and shown to be present at a low frequency of heterozygosity $(0.004 \%)$ in 570 participants of European descent (NCBI, 2013). Our sample showed a high frequency, probably representing difference in ethnic background.

The amino acid glycine at position 149 is located in the transmembrane domain of the enzyme glucose 6-phosphate translocase, and the substitution of glycine to glutamic acid (p.G149E) changes the conformation of this enzyme. It is a rare change that has been reported only once in a Chinese family (Lam et al., 2000).

Finally, the present study allowed the identification of a new mutation, c.1338_1339insT, in individual 8. This patient is the fourth child of a consanguineous couple (first cousins) of Italian origin, whose third child died at the age of seven months with similar clinical symptoms. Pregnancy was complicated by maternal hypertension, and delivery was at 38 weeks of gestational age, weighting 3,590 $\mathrm{g}$ and measuring $51 \mathrm{~cm}$. The child had hyperbilirubinemia after $48 \mathrm{~h}$ requiring exchange transfusion, and was released at the $5^{\text {th }}$ day after birth. At 10 days, a single convulsion was documented and at the age of three months hepatomegaly was denoted. During investigation, glycemia after fasting was $2 \mathrm{mg}$, total cholesterol was $251 \mathrm{mg} \%$, and triglyceride $814 \mathrm{mg} \%$ (both with a reference value: $<200$ ), alkaline phosphatase was $477 \mathrm{IU} / \mathrm{L}$ (reference value: < 400), and CK 144 IU/L (reference value: < 190). Liver biopsy was 
performed for a histological study, which was compatible with GSD. After starting treatment with frequent meals, cornstarch, and dietary restriction of lipids and sugars (fructose, lactose, galactose, and sucrose), he presented normal neuromotor and somatic development, reaching a final height of $189 \mathrm{~cm}$. Nevertheless, biochemical followup revealed variable degrees of hypercholesterolemia and hypertriglyceridemia, and he also developed hyperurice$\mathrm{mia}$ at the age of nine years, which was treated with $200 \mathrm{mg}$ allopurinol twice a day. Renal function was always normal and neutropenia was never seen during routine exams, but at the age of 23 he presented an acute episode of sepsis and died after two days in another hospital with no further information available.

Although functional studies could not be performed to confirm that this mutation causes the disease, some aspects support the hypothesis. First, the insertion of the T base changed the reading frame, resulting in a different amino acid sequence and a premature stop codon. Second, no other causative mutation was found in this individual. Finally, the presence of parental consanguinity is compatible with the finding of this mutation in homozygosity.

In seven patients with clinical symptoms suggestive of GSDla and GSDIb no mutation was found in coding regions (exons) or adjacent introns. Mutations in other parts of the gene, including introns, were not studied, but it seems unlikely that they may cause an abnormal phenotype in these individuals. An alternative explanation to the negative results in this molecular study is the possibility of a misdiagnosis, since even with a careful evaluation based on laboratory and clinical findings, overlap with other types of GSD is possible. Thus further molecular studies would be indicated.

The molecular analysis of the two genes enabled diagnosis confirmation of GSDIa and $\mathrm{Ib}$ in four patients, without the need for liver biopsy. In addition, the identification of the mutation provided an additional tool for genetic counseling. Despite the limited number of subjects, our results showing that p.R83C was the most frequent mutation in G6PC in the present sample is compatible with international (Lei et al., 1995a,b; Parvari et al., 1995, 1997; Stroppiano et al., 1999; Rake et al., 2000) and previous Brazilian studies (Reis et al., 2001). Thus, in every patient with GSD $\mathrm{Ia}$ or $\mathrm{Ib}$, we propose to start with an investigation of this mutation and then to sequence the $G 6 P C$ gene. For patients without identifiable genetic mutations, enzymatic essay or a further molecular study of other GSD genes remain diagnostic tools. Finally, in this study a new mutation was found and described.

\section{References}

Burchell A (1990) Molecular pathology of glucose-6-phosphatase. FASEB J 4:2978-2988.

Chen YT (2001) Glycogen storage disease. In: Scriver CR, Beaudet AL, Sly WS and Valle D (eds) The Metabolic and
Molecular Bases of Inherited Disease. McGraw Hill, New York, pp 1521-1551.

Chevalier-Porst F, Bozon D, Bonardot AM, Bruni N, Mithieux G, Mathieu M and Maire I (1996) Mutation analysis in 24 French patients with glycogen storage disease type 1a. J Med Genet 33:358-360.

Chou JY, Matern D, Mansfield BC and Chen YT (2002) Type I glycogen storage diseases: Disorders of the glucose-6-phosphatase complex. Curr Mol Med 2:121-143.

Diament A, Schmidt BJ and Ramos JLA (1994) Erros inatos do metabolismo. In: Marcondes E (ed) Pediatria Básica. Sarvier, São Paulo, pp 722-726.

Fernandes J, Huijing F and Van de Kamer JH (1969) A screening method for liver glycogen diseases. Arch Dis Child 44:311317.

Froissart R, Piraud M, Boudjemline AM, Vianey-Saban C, Petit F, Hubert-Buron A, Eberchweiler PT, Gajdos V and Labrune P (2011) Glucose-6-phosphatase deficiency. Orphanet J Rare Dis 6:27.

Gerin I, Veiga-da-Cunha M, Achouri Y, Collet J and Schaftingen EV (1997) Sequence of a putative glucose 6-phosphate translocase, mutated in glycogen storage disease type $1 \mathrm{~b}$. FEBS Lett 419:235-238.

Gitzelmann R and Bosshard NU (1993) Defective neutrophil and monocyte functions in glycogen storage disease type $\mathrm{Ib}: \mathrm{A}$ literature review. Eur J Pediatr 152(Suppl 1):S33-S38.

Hicks J, Wartchow E and Mierau G. (2011) Glycogen storage diseases: A brief review and update on clinical features, genetic abnormalities, pathologic features, and treatment. Ultrastruct Pathol 35:183-196.

Kure S, Hou DC, Suzuki Y, Yamagishi A, Hiratsuka M, Fukuda T, Sugie H, Kondo N, Matsubara Y and Narisawa K (2000) Glycogen storage disease type Ib without neutropenia. J Pediatr 137:253-256.

Lam WC, Sin SY, Lau ET, Lam YY, Poon P and Tong SF (2000) Prenatal diagnosis of glycogen storage disease type $1 \mathrm{~b}$ using desnaturing high performance liquid chromatography. Prenat Diag 20:765-768.

Lei KJ, Shelly LL, Pan C, Sidbury JB and Chou JY (1993) Mutations in the glucose 6-phosphatase gene that cause glycogen storage disease type 1a. Science 262:580.

Lei KJ, Pan CJ, Shelly LL, Liu JL and Chou JY (1994) Identification of mutations in the gene for glucose-6-phosphatase, the enzyme deficient in glycogen storage disease type 1a. J Clin Invest 93:1994-1999.

Lei KJ, Shelly LL, Baochuan L, Sidbury JB, Chen Y and Nordlie RC (1995a) Mutations in the glucose 6-phosphatase gene are associated with glycogen storage disease types 1a and $1 \mathrm{aSP}$ but not $1 \mathrm{~b}$ and $1 \mathrm{c}$. J Clin Invest 95:234-240.

Lei KJ, Chen YT, Chen H, Wong LJ, Liu JL, McConkie-Rosell A, Van Hove JL, Ou HC, Pan LY, et al. (1995b) Genetic basis of glycogen storage disease type Ia: Prevalent mutations at the glucose-6-phosphatase locus. Am J Hum Genet 57:766771.

Marcolongo P, Barone V, Priori G, Pirola B, Giglio S, Zammarchi E, Parenti G, Burchell A, Benedetti A and Sorrentino V (1998) Structure and mutation analysis of the glycogen storage disease type $1 \mathrm{~b}$ gene. FEBS Lett 436:247-250.

Martens DH, Kuijpers TW, Maianski NA, Rake JP, Smit GP and Visser G (2006) A patient with common glycogen storage 
disease type Ib mutations without neutropenia or neutrophil dysfunction. J Inherit Metab Dis 29:224-225.

Moses SW (1990) Pathophysiology and dietary treatment of the glycogen storage diseases J Pediatr Gastroenterol Nutr 11:155-174.

Parvari R, Lei KJ, Bashan N, Hershkovitz E, Korman SH, Barash V, Lerman-Sagie T, Mandel H, Chou JY and Moses SW (1997) Glycogen storage disease type 1a in Israel. Biochemical, clinical, and mutational studies. Am J Med Genet 72:286-290.

Parvari R, Moses S, Hershkovitz E, Carmi R and Bashan N (1995) Characterization of the mutations in the glucose-6-phosphatase gene in Israeli patients with glycogen storage disease type 1a: R83C in six Jews and a novel V166G mutation in a Muslim Arab. J Inher Metab Dis 18:21-27.

Rake JP, ten Berg AM, Verlind E, Visser G, Niezen-Koning KE, Buys CH, Smit GP and Scheffer H (1999) Glycogen storage disease type1a: Four novel mutations (175delGG, R170X, G266V and V338F) identified. Hum Mutat 13:173-176.

Rake JP, Ten Berge AM, Verlind E, Niezen-Koning KE, Buys $\mathrm{CH}$, Smit GP and Scheffer H (2000) Glycogen storage disease type 1a: Recent experience with mutation analysis, a summary of mutations reported in the literature and a newly developed diagnostic flowchart. Eur J Pediatr 159:322-330.

Reis FC, Caldas HC, Norato DY, Schwartz IV, Giugliani R, Burin MG and Sartorato EL (2001) Glycogen storage disease type Ia: Molecular study in Brazilian patients. J Hum Genet 46:146-149.
Rubin E, Gorstein F, Schwarting R, Rubin R and Strayer D (2006) Patologia - Bases Clinicopatológicas da Medicina. 6th ed. Guanabara Koogan, Rio de Janeiro, pp 1648.

Stroppiano M, Regis S, DiRocco M, Caroli F, Gandullia P and Gatti R (1999) Mutations in the glucose-6-phosphatase gene of 53 Italian patients with glycogen storage disease type Ia. J Inherit Metab Dis 22:43-49.

Tamhankar PM, Boggula V, Girisha KM and Phadke SR (2012) Profile of patients with Von Gierke disease from India. Indian Pediatr 49:228-230.

van Schaftingen E and Gerin I (2002) The glucose-6-phosphatase system. Biochem J 362:513-532.

Visser G, Rake JP, Fernandes J, Labrune P, Leonard JV, Moses S, Ullrich K and Smit GP (2000) Neutropenia, neutrophil dysfunction, and inflammatory bowel disease in glycogen storage disease type Ib: Results of the European Study on Glycogen Storage Disease type I. J Pediatr 137:187-191.

\section{Internet Resources}

National Center for Biotechnology Information (NCBI), http://www.ncbi.nlm.nih.gov/pro-

jects/SNP/snp_ss.cgi?ss=ss491655203 (October 29, 2013).

Associate Editor: Carlos F.M. Menck

License information: This is an open-access article distributed under the terms of the Creative Commons Attribution License, which permits unrestricted use, distribution, and reproduction in any medium, provided the original work is properly cited. 